reservoir should always be about i 5 lbs. above that in the train-pipe, so that when the brakes are being relcased by increasing the pressure in the train-pipe dircot from the main reservoir, the triple valves are certain to act, on account of the extra 15 lbs. pressure in the train-pipe above the pressure in the small reservoirs.

On moving the handle of the driver's valve further in the same direction, or into the position for applying the brakcs, all connection between the main reservoir and the train-pipe is cut off, at the same time that the trainpipe is put in conncction with the atmosphere, through an exhaust port; by this means the pressure in the trainpipe can be reduced to any degree to apply the brake. All brake-cylinders on vehicles are fitted with a releasevalve, so that, should the brake be applied when the engine is not attached, the air can be discharged from the brake-cylinder, through the release-valve, by pulling a wire attached to the valve.

All vehicles now fitted with this brake have cocks at each end of the train-pipe, so that, should any change have to be made in the train, the coupling or uncoupling of vehicles is easily accomplished without the brake automatically applying itself.

It is easy to see that this brake is autoriatic in its action, for should the train-pipe or flexiljle couplings be injured by accident, or the train part into two or more portions, the compressed air will cscape from the train pipe, and the brake will apply itself. In all guards' vans is placed a cock in connection with the train-pipe, so that, should the guard observe anything wrong with the train, or receive a signal from a passenger, he can instantaneously apply the brake by opening the cock and discharging the air from the train-pipe.

The Westinghouse automatic brake is at present the only one which really includes all the qualitics in the Board of Trade requirements for continuous brakes, and perhaps it will not be out of place to state the requirements of the Board of Trade.

(I) The brakes to be efficient in stopping trains, instantaneous in their action, capable of being applied without difficulty by engine-clrivers and guards.

(2) In cases of accident, to be instantaneously self acting.

(3) The brakes to be put on and taken off (with facility) on the engine and cvery vehicle of a train.

(4) The brakes to be used in daily working.

(5) The material employed to be of a durable character, so as to be easily maintained and kept in order.

On looking through the Board of Trade returns on continuous brakes for the six months ending June 30 , one sees that over two-thirds of the failures of the Westinghousc automatic are due to burst hose pipes alone, and therefore not failures of the brake itself, but of faulty inspection and bad matcrial. We would like to hear of experiments being made with a stronger and more durable material, so as to resist the destructive action of the oil and tallow, of which such a large quantity is used on railways. Could this improvement be effected, we are convinced the number of miles rum per failure would immediately vastly increase, leaving the altomatic vacuum brake far behind. Of failures of the triple valve to act we find fifteen reports, causing a very trifling delay to the trains. The air-pump is reported with eleven failures, and the driver's brake-valve has no failurcs recorded against it. When we consider the enormous mileage of $15,505,447$ miles run by trains fitted with the Westinghouse automatic for the six months ending June 30 , we cannot help being astonished at the freedom from failure of the different parts, and the general efficiency of the apparatus.

Much has been written about the failure of the simple vacuum brake in the Penistone accident on the Manchester, Shcffield, and Lincolnshire Railway, the disaster being attributed by some to the brake failure alone. Certainly, had the train been fitted with the
Westinghouse automatic, the brake power on each vehicle would have remained intact, no matter how many couplings broke: but at the same time the fact seems to have been overlooked that the train had no permanent way to run on, since the engine broke up the chairs as it advanced, and the question remains, How would the train have been affected, having nearly all the wheels locked by the brake, and running over sleepers alone? Perhaps the train would not have travelled so far before going over the embankment; but we think the disaster would have been equally serious, each vehicle becoming detached by the sudden application of the brake, the couplings breaking on account of the violent jerks in passing over the sleepers, the curve tending to throw the vehicles over the embankment. As an example of the life-saving qualities of an automatic brakc in an accident, we think the Penistone disaster would have been a poor specimen.

The question of automatic versus simple brakes, both pressure and vacuum, is now fairly before the public, and the policy of the Board of Trade seems more apparent every day. It would not be wise on their part to enforce the adoption of any particular patent brake, for a better one may any day be discovered, but the Board may fairly insist that their conditions as to the qualities of any brake adopted by any Company should be complied with, and, if necessary, enforced by Act of Parliament.

\section{THE GALVANOMETER OF D'ARSONVAL AND DEP'REZ}

CALVANOMETERS of innumerable kinds abound, and each form has some special merit which renders it useful for certain restricted services. The old astatic instrument of Nobili is still preferred by many to the more modern mirror galvanometer of Sir W. Thomson because it requires no lamp, and can be used without clarkening the room. The tangent galvanometer still holds its own in the testing-room for simple tests; and the lineman's detector is still indispensable on the score of its portability. For commcrcial purposes, where strong currents and steady potentials have to be mcasurcd, the newer ampere-meters and volt-meters have displaced the older forms of instrument. But still there is no best galvanometer of universal adaptability, even the Siemens "universal" galvanometer being too clumsy to mect with gencral favour.

For the purposes of the private laboratory a galvanometer is desired which shall be sensitive, yet accurate in its indications, capable of being used for measuring currents of all kinds, weak and strong, and of measuring differences of potential from the thousandth of a volt to a thousand volts. It ought to be capablc of bcing used in broad daylight; of being rapidly read off ; and it ought also to be independent of external magnetic disturbances. The annoyances which arise from the last two causes when working with sensitive galvanometers are only too well known. The needle of the instrument once deflected continucs to oscillate perhaps for half a minute, perhaps longcr, causing vexatious delays, and when perhaps it has settled down at last to zero, some person in the next room moves a piece of iron-a poker, a penknife, or some other magnetic object-causing the zcro of the instrument to change. An aperiodic dead-beat instrument, not subject to external magnetic forces, would be a boon indeed.

A galvanometer' which, without being absolutely perfect, goes very near to fulfilling these desirable conditions has lately been put into the hands of electricians by M. Carpentier, of I'aris, successor to the well-known Ruhmkorff. It is the invention of M. Marcel Deprez as modified and improved by Dr. d'Arsonval. The many novel features which it presents would of themselves justify its description in the pages of NATURF; and the general excellence 
of its performance, of which the writer of these lines can personally testify, is already widely acknowledged.

The main peculiarity of the new instrument lies in the fact that, whereas in almost all galvanometers there is a fixed coil and a movable magnetic needle, in this galvanometer the coil is movable and the magnet-no longer a mere needle but a substantial compound horseshoe of steel-is fixed. Fig. I represents the instrument itself. The steel magnet, made of three thin horse-shoes each magnetised as strongly as possible, is firmly fixed to a metal base, with its poles upwards. Between the poles hangs the coil, rectangular in form and extremely light, held in its place by a thin silver wire above and another thin silver wire below. This coil is made by winding on a rectangular core, which, after the strands have been cemented and bound together, is removed, leaving the wire only. It weighs only a few grains. To reinforce the magnetic field a small cylinder of soft iron, small enough to lie in the hollow of the suspended rectangular coil without touching it, is placed between the poles and is rigidly supported from behind. The coil is then free to turn in the very narrow space between the

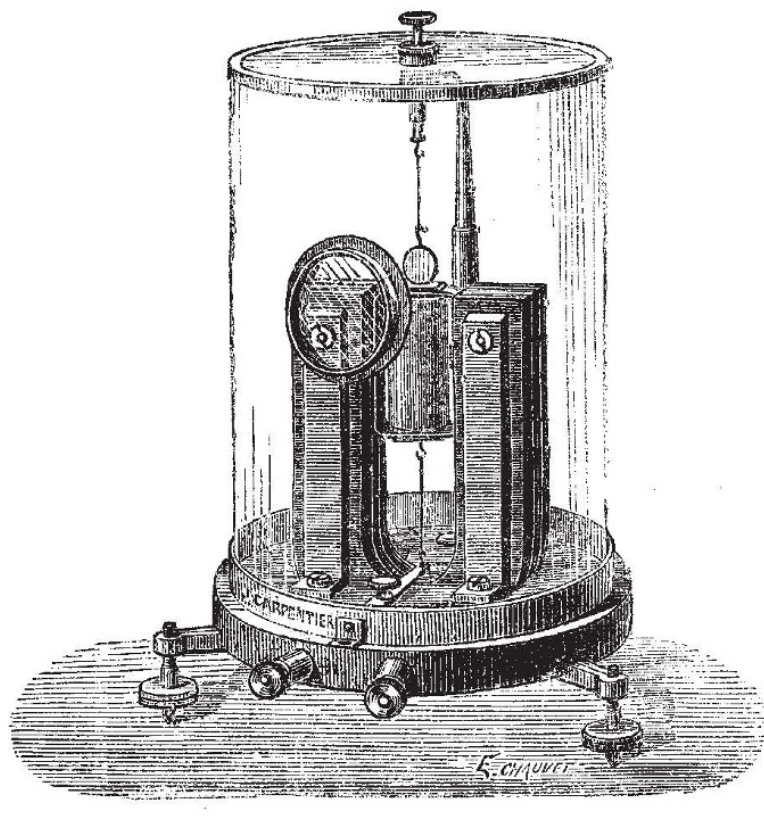

Fir. I.

iron core and the external magnet-poles; and it need hardly be added that this contrivance produces a very intense magnetic field. The current is led in by one of the silver suspension-wires, and leaves the coil by the other. So far the arrangement precisely resembles that adopted in the well-known "siphon-recorder" of Sir W. Thomson, invented twenty years ago for the purpose of cable-signalling. A small mirror of $\mathrm{I}$ metre focus is affixed to the suspended coil ; a brass spring at the bottom keeps the suspending wires adequately stretched; and a screwhead at the top of the instrument serves both to regulate the tension in the wires and to let the coil down, to a position of rest on the central iron cylinder, whenever the galvanometer is to be dismounted for removal to a distant place. The resistance of the coil is about 150 ohms in the ordinary pattern of instrument. As there is no suspended needle, no external magnetic forces affect the zero of the instrument; and, since the position of the coil is determined solely by the elasticity of the suspending wires and the magnetic action of the fixed magnet on the current in the coil, it can be used in any position, and is independent of the earth's magnetic field. It can even be placed quite near to a dynamo-machine. The intensity of the magnetic field in which the coil is situated is such that whenever the galvanometer-circuit is closed-even through a considerable resistance-the motion of the needle is dead-beat. It takes less than one second to come to rest at its final position of deflection, and when it returns to zero it does so with the most complete absence of oscillations. The spot of light on the scale never oscillates so much as I millimetre over the zero on releasing the galvanometer-key.

The optical arrangements adopted by M. Carpentier are shown in Fig. 2. The instrument is set with its three levelling screws in three $\mathrm{V}$-grooves in a convenient bedplate. Opposite it is set a semi-transparent scale of celluloid, 50 centimetres in length, graduated in millimetres. The light is provided by a single wax candle held in a holder like a carriage-candle, which also carries a paraboloidal mirror back. This candle is set so that its light falls upon a small adjustable plane mirror fixed to the back of the scale. This mirror reflects the ray upon the small mirror of the galvanometer, but as it passes beneath the scale it traverses a square aperture across which a thin wire is stretched vertically. To sec the spot of light the observer stations himself in front of the scale, so as to see the light coming through the strip

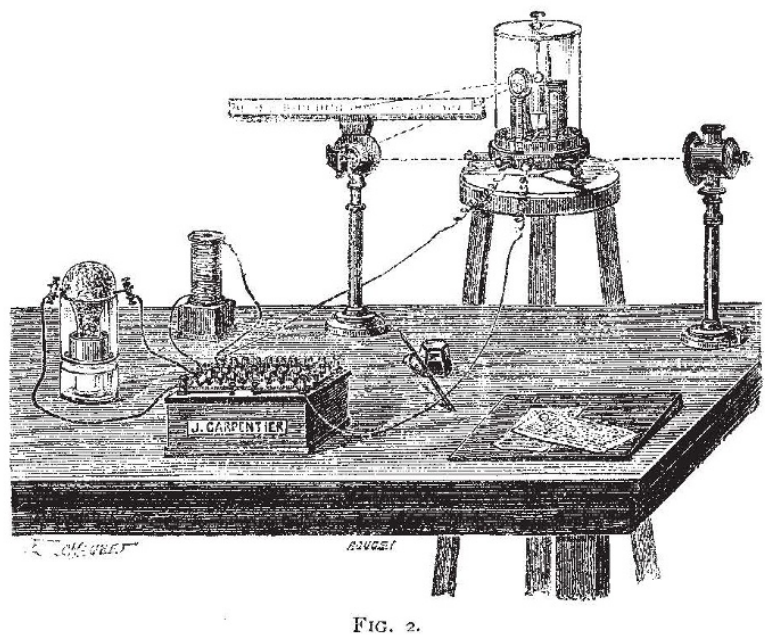

of celluloid. He sees a bright patch about $\mathbf{I}$ inch square having a single sharply-defined black line-the image of the aforesaid wirc-down its middle. This patch of light and the central line are perfectly visible in broad daylight, but cannot be well seen by more than one observer at one time. The adjustment of the lamp and scale is a simple matter; and light from any lamp in the room-an overhead gas-light for example - may be used instead by turning the adjustable mirror to the proper angle.

When set up without any shunt, this galvanometer will show a deffection of I millimetre on the scale for about $I / 100,000,000$ of an ampere of current : but the sensitiveness differs in different instruments with the construction of the coil, the stiffness of the suspension, and the power of the magnets. Two instances of its application may be given.

The instrument can be applied as a volt-meter to measure the electromotive forces of cells in the manner indicated in Fig. 3. An ordinary reversing-key, $K$, is connected to the galvanometer, and an adjustable resistance (a Wheatstone rheostat with a thin wire having a range from I to 200 ohms is convenient) is interposed as a shunt, $\mathrm{s}$. To calibrate the instrument a standard Daniell cell (E.M.F. $=I^{\circ} O 7$ volt) is placed at $\mathrm{B}$ in circuit with a resistance box. $A$ resistance of 10,000 ohms is unplugged and a reading 
is taken of the galvanometer, first to left, then to right, and the shunt-resistance is then adjusted until the scale reading is $53 \frac{1}{2}$ millimetres on either side of zero, making a total of 107 millimetres. We then know that a deflection of I millimetre right or left will be produccd by an electromotive force of $\mathrm{I} / 200$ of a volt. The cell whose electromotive force is to be tested is then substituted at $\mathrm{B}$ in place of the standard cell, and readings taken right and left ; these are added, and divided by 100 , giving the E.M.F. of the cell directly in volts.

To measure currents the same calibration is made with a standard cell. In the circuit of the current to be measured is interposed a wire of some small but accuratelyknown resistance-for example, a standard $\mathrm{I}$ ohm, or, for stronger currents, a standard wire of $\mathrm{O}^{\circ} \mathrm{I}$ ohm. The two extremities of this coil are then connected to the key (Fig. 3), the I0,000-ohm coil being interposed as before. If the current to be measured is I ampere, it will, in passing through the standard $\mathrm{I}$ ohm, produc

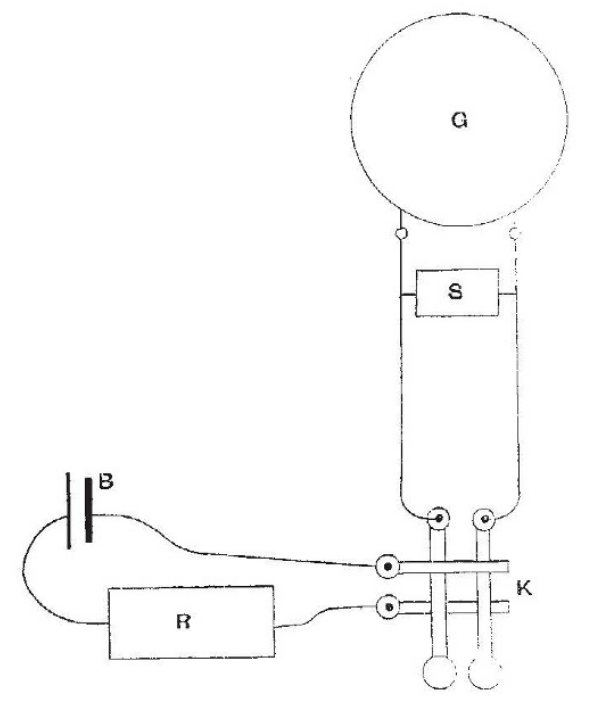

Fig. 3.

between its ends a difference of potential of $\mathrm{I}$ volt, and this difference of potential will, when readings are taken right and left, give a total defiection of 100 millimetres to correspond to I ampere of current. It is not difficult to modify the arrangements so that the galvanometer may measure, on the one hand, millionths of an ampere, and thousands of amperes on the other. We have found the instrument specially valuable for indicating rapid fluctuations of current in experiments on the induction of currents in armature coils when moved in a magnetic field. Its complete aperiodicity and the very small inertia, both mechanical and electrical, of its coil, render it most valuable for such work. The only defect-and that not a serious one-observed in three months of use, is a slight sub-permanent torsion on the suspending wires after taking a large deflection; but the method of taking double readings, first to right, then to left, climinates any error that might arise from this cause.

\section{THE BASALT-FIELDS OF NEW MEXICO}

CELOGISTS interested in the history of the younger G lava-floods, by which such vast areas both in the Old World and in the New have been deluged, will be glad to know that Capt. Dutton, of the United States Ceological Survey, after a careful study of the modern volcanic phenomena of the Sandwich Islands, has under$\mathrm{t}^{\text {aken }}$ the investigation of the basalt-territory lying in
New Mexico, to the east and south of the area already so fully described by him in his Monographs on the Utah plateaux and the Cañon country. It was originally intended that he should have charge of the Survey of the Cascade Range. This arrangement was changed at the beginning of this last season. The Cascade ground was intrusted to his able assistant, Mr. Diller, while Capt. Dutton himself struck southward for a region in New Mexico, which he had long wished to study, from the light which he believed it would throw upon some of the later phases of volcanism in the Western Territories. I have received a long letter from him, written in his camp at the San Mateo Mountains, from which, with his permission, I send the following extract for publication in NATURE.

ARCH. GeIKIF.

Our wonderful Plateau Country we have known only in part, and the portion we have studied most is situated upon the western and northern side of the Colorado. Numerous geologists have hurried over the southern and south-eastern portion ; but so rapidly have they been obliged to move in order to keep pace with the expeditions of which they were merc appendages that very little systematic knowledge could be gained. During the last two years our topographers have made some excellent maps of this region, and everything is ripe for the geologist.

I have described the western and southern portions of the Plateau Country as being very sharply defined in a geological as well as in a topographic sense. I think it will in great part prove to be equally well-defined in the south-eastern portions. Already it is clear to me that the Rio Grande River constitutes a portion of that boundary in this territory. Everywhere within range of my present field the strata characteristic of the Plateau Country rise gently from the Rio Grande to the westward. Cliffs, mesas, and terraces, carved buttes, and gorgeous colours are as typical of this region as they are of Utah and Northern Arizona. There is, however, more of the Cretaceous system preserved, and rocks of that age predominate, though the Trias and Permian are magnificently exposed. Indeed, the Vermilion Cliffs of Southern Utah have reappeared here in all their grandeur and glory, with but slight changes of detail.

But the features which are engaging my particular attention at this moment are the volcanic vestiges. This region has long been known under the mysterious name of Malpais-mysterious, however, only to those who have not read Humboldt's account of the malpais of Old Mexico. All the mesas, or platforms of sedimentary beds, within three or four miles of my camp, are sheeted over with basalt. The lava caps are not ordinarily more than fifty or a hundred feet thick; though just around me, in the very centre or focus of all, it bccomes much thicker. In the valley-plains, also, are found many sheets of lava. But while the lavas upon the higher platforms and terraces are ancient, those in the valleys are very young. The centre of the activity has been (so far as concerns my present vicinity) the San Mateo Mountains. This name is synonymous with Mount Taylor, for the "Mountains" consist of a single volcanic pilc ( 11,380 feet) carved into numerous spurs by magnificent gorges. It is a small Etna, built originally by outbreaks from its flanks as well as its summit. But the spread of the lavas from this centre is remarkable. To the north-north-east they reach out in unbroken continuity for forty-five miles, and for eighteen to thirty miles in the other directions. The lava beyond the immediate base of the mountaincone is not thick. It forms a superficial sheet only on each mesa, or table, with a thickness varying from 50 to 200 feet.

The lava-capped strata have been cut into isolated mesas by subsequent crosion, and gaps of two or three miles sometimes separate one of these outliers from its parent mass. 